\title{
Otomatisasi Mesin Capping Untuk Botol Obat Sirup di PT. Mersifarma Tirmaku Mercusana Sukabumi
}

\author{
Lukas B. Setyawan \\ Program Studi Teknik Elektro, \\ Fakultas Teknik Elektronika dan Komputer, \\ Universitas Kristen Satya Wacana, Salatiga \\ Email : lukas.setyawan@staff.uksw.edu
}

\begin{abstract}
Ringkasan
Mesin capping digunakan untuk menyegel kemasan botol kaca atau botol plastik dengan tutup berbahan logam. Otomatisasi mesin capping untuk botol obat sirup di PT. Mersifarma Tirmaku Mercusana, Sukabumi, Jawa Barat ini dilakukan untuk meningkatkan kapasitas produksi dan memperkecil jumlah produk gagal pada proses pengemasan sirup (liquid syrup) dan sirup kering (dry syrup). Sistem mesin capping ini menyediakan 4 pilihan ukuran botol, yaitu $60 \mathrm{ml}, 75 \mathrm{ml}, 100 \mathrm{ml}$, dan 120ml. Masukan mesin capping ini adalah botol dengan tutup belum tersegel. Sedangkan keluarannya adalah botol telah tersegel. Mesin capping ini untuk ukuran botol $60 \mathrm{ml}$ mengalami peningkatan kapasitas produksi sebesar $30 \%$ dan produk gagal menurun $79 \%$. Untuk ukuran botol $75 \mathrm{ml}$ mengalami peningkatan kapasitas produksi sebesar 30\% dan produk gagal menurun 79\%. Untuk ukuran botol $100 \mathrm{ml}$ mengalami peningkatan kapasitas produksi sebesar 33\% dan produk gagal menurun $75 \%$. Untuk ukuran botol $120 \mathrm{ml}$ mengalami peningkatan kapasitas produksi sebesar $36 \%$ dan produk gagal menurun $77 \%$.
\end{abstract}

Kata kunci: otomatisasi mesin capping, pengemasan botol obat sirup, peningkatan kapasitas produksi, penurunan jumlah produk gagal

\section{Pendahuluan}

Mesin capping adalah mesin pengemasan yang digunakan untuk menyegel kemasan berupa botol, baik botol plastik maupun botol kaca. Mesin capping digunakan untuk menutup atau mengulir tutup botol dengan ulir pada botolnya, umumnya menggunakan tutup botol berbahan logam. Mesin penutup botol diperlukan untuk pengemasan primer pada produksi obat sirup. Pada proses penutupan botol secara manual kapasitas pengemasan tidak konsisten. Proses crimping menggunakan teknik tekanan untuk mendorong tutup logam pada botol untuk proses segelisasi mengakibatkan jumlah produk gagal cukup besar. Dengan melakukan otomatisasi diharapkan terjadi penurunan produk gagal sekaligus meningkatkan kapasitas produksi. Otomatisasi mesin capping ini dilakukan di PT. Mersifarma Tirmaku Mercusana, Sukabumi, Jawa Barat.

Pembahasan dimulai dengan penjelasan sistem otomatisasi meliputi proses kerja sistem, sistem mekanik, dan sistem elektronik. Kemudian dilanjutkan dengan hasil pengujian dan diakhiri dengan kesimpulan. 


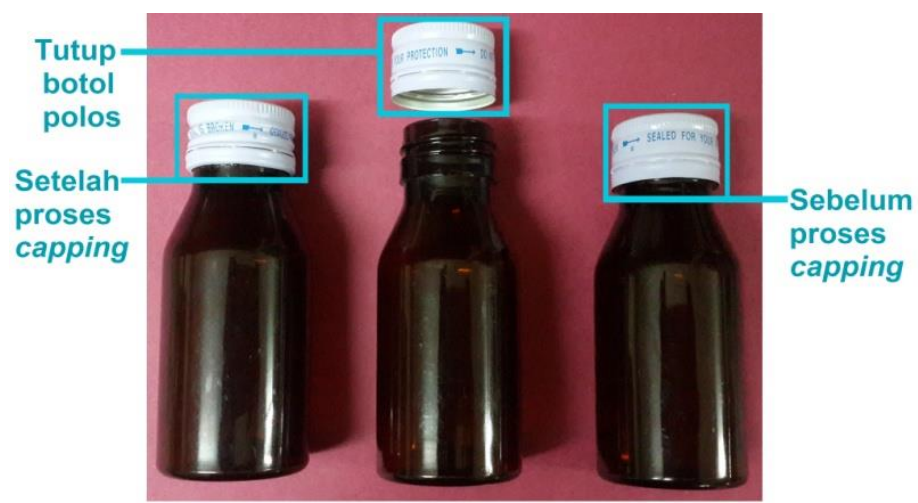

Gambar 1. Botol sebelum dan setelah proses capping

\section{Sistem Otomatisasi Mesin Capping}

Otomatisasi dilakukan dengan penambahan menu pilihan empat ukuran botol yang sering digunakan dengan pengaturan ketinggian pada masing-masing ukuran botol secara otomatis. Penambahan starwheel yang dikontrol melalui mikrokontroler arduino mega 2560, bertujuan untuk membawa atau menggeser botol tepat di bawah crimping head. Penambahan sistem conveyor untuk memudahkan peletakan botol menuju mesin capping.

\subsection{Proses Kerja Sistem}

Masukan dari mesin capping berupa botol dengan tutup aluminium polos tanpa ulir dan keluaran dari mesin ini adalah botol dengan tutup botol yang sudah tersegel dan terbentuk ulir pada tutup botol aluminiumnya.

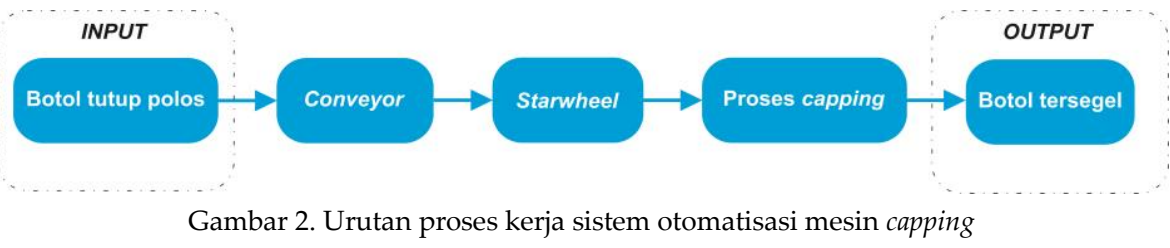

\subsection{Sistem Mesin Capping}

Gambar sketsa mesin capping ditunjukkan pada Gambar 3. Mesin capping di kontrol melalui mikrokontroler untuk memberikan perintah menggerakkan starwheel (f) dan alat crimping (g). Botol dengan tutup polos (b) yang berada di atas conveyor akan berjalan menuju starwheel. Starwheel akan bergeser membawa botol dengan tutup polos menuju tepat di bawah alat crimping, selanjutya botol akan di tutup secara mekanis menggunakan alat crimping. Botol yang sudah tertutup atau sudah tersegel (e) akan menuju ke meja untuk botol yang telah tersegel. 


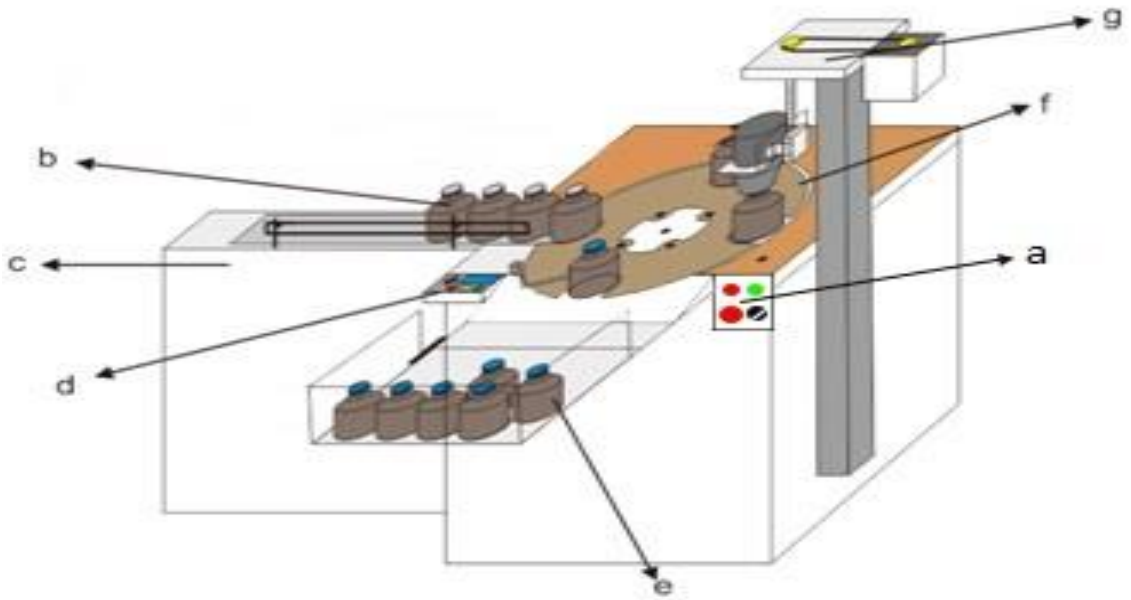

Keterangan:

a : Tombol on/off, emergency switch.

$\mathrm{b}:$ botol dengan tutup polos.

c : conveyor.

$\mathrm{d}$ : control panel (push button switch keypad dan $L C D$ ).

e : botol dengan tutup terulir.

$\mathrm{f}:$ starwheel.

$\mathrm{g}$ : alat crimping.

Gambar 3. Gambar sketsa mesin capping
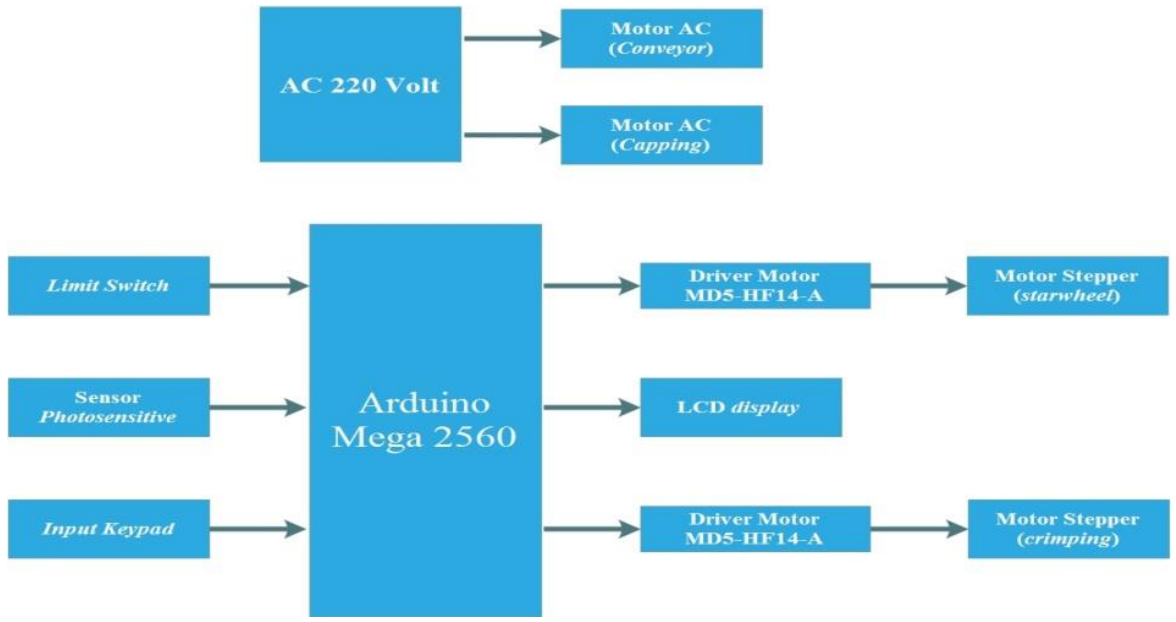

Gambar 4. Diagram Blok Alat.

Arduino Mega 2560 digunakan sebagai pusat kontrol pada sistem elektronik mesin capping. Menggunakan keypad sebagai tombol input dan LCD sebagai penampil menu dari mesin capping. Mikrokontroler akan mengolah data yang diterima dari user dan diproses untuk menggerakkan motor stepper melalui driver motor stepper. User dapat memilih ukuran botol yang akan dicapping melalui user interface, yaitu menu yang tertampil pada LCD dan input dari keypad.

\subsection{Sistem Mekanik}

Sistem mekanik pada mesin capping ini terbagi menjadi 4 modul yang terdiri dari conveyor, starwheel, alat crimping dan capping head. Berikut mekanik masing-masing modul. 


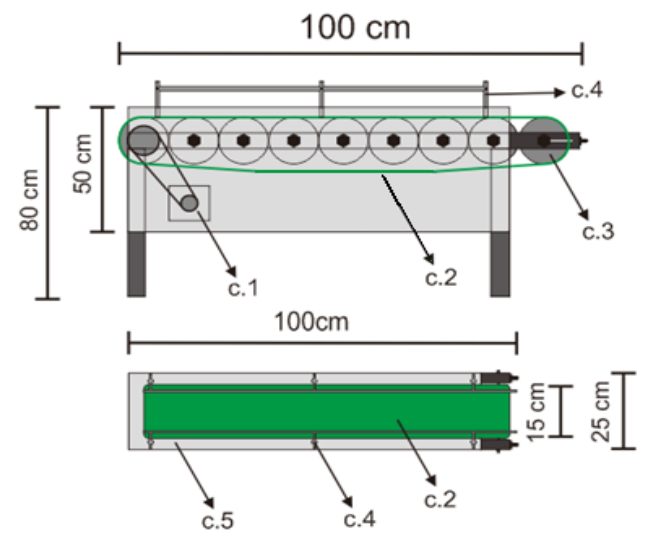

Keterangan :

c. $1:$ motor ac.

c. 2 : belt conveyor.

c. 3 : head pulley.

c. 4 : guide bar.

c.5 : rangka conveyor.

Gambar 5. Modul Conveyor.

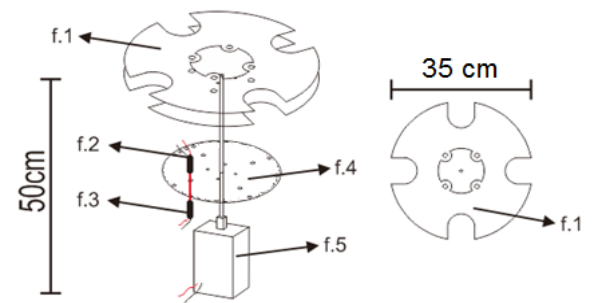

Keterangan :

f.1 : piringan starwheel.

f.2 : sensor photosensitive.

f.3 : laser modul.

f. 4 : piringan sensor.

f.5 : motor stepper.

Gambar 6. Modul Starwheel dan sensor.

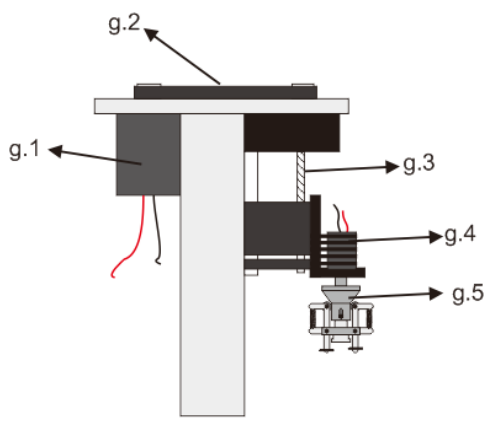

Keterangan :

g.1 : motor stepper.

g.2 : belt dan pulley.

g.3 : ulir.

g.4 : motor ac.

g.5 : capping head.

Gambar 7. Sistem crimping. 


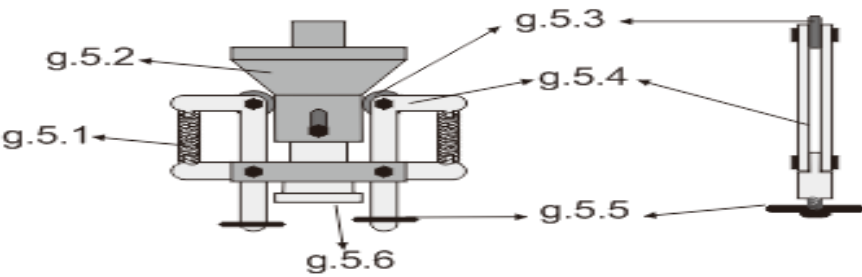

Keterangan :

g.5.1 : per pegas

g.5.2 : capping base.

g. 5.3 : bearing.

g.5.4 : lengan mekanis.

g.5.5 : pisau pembentuk ulir.

g.5.6 : dudukan tutup botol.

Gambar 8. Modul Capping head.

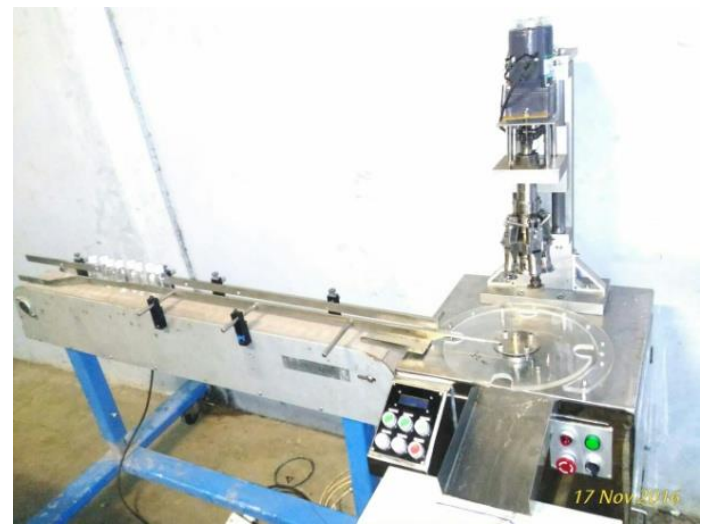

Gambar 9. Realisasi mesin capping.

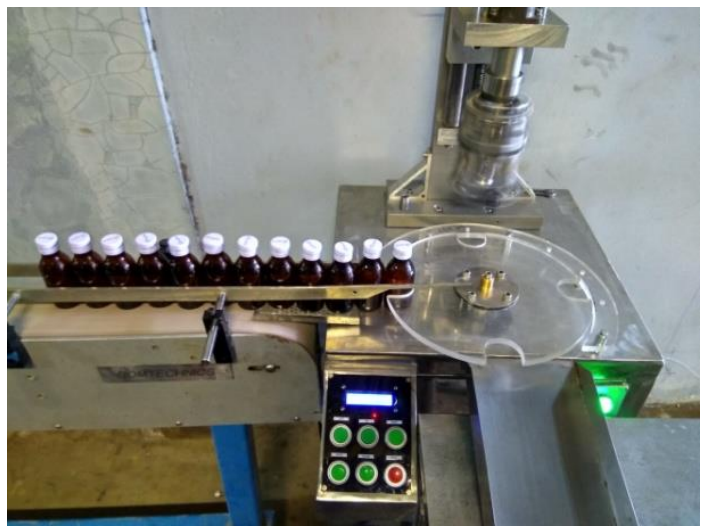

Gambar 10. Mesin capping.sedang bekerja

\subsection{Sistem Elektronik}

Sistem elektronik pada mesin capping terdiri dari mikrokontroler Arduino Mega 2560. sensor, motor stepper dan driver, serta user interface. User melakukan konfigurasi melalui user interface untuk memilih ukuran botol. Mikrokontroler akan menggerakkan motor crimping pada posisi ketinggian awal hingga menyentuh limit switch dan menggerakkan motor starwheel ccw hingga mikrokontroler memperoleh logika high dari kedua sensor. Setelah proses tersebut terlewati, mikrokontroler akan memberi perintah kepada motor starwheel untuk bergerak cw sebesar 90 derajat. Kemudian motor crimping akan berputar ccw untuk menurunkan capping head hingga ketinggian yang sudah dipilih oleh user 
melalui menu yang tertampil. Setelah 1 sekon motor crimping akan berputar $\mathrm{cw}$ untuk menaikkan capping head pada posisi ketinggian awal. Proses ini berulang terus hingga user mematikan alat. Perangkat lunak sistem mesin capping diperlihatkan oleh Gambar 11.

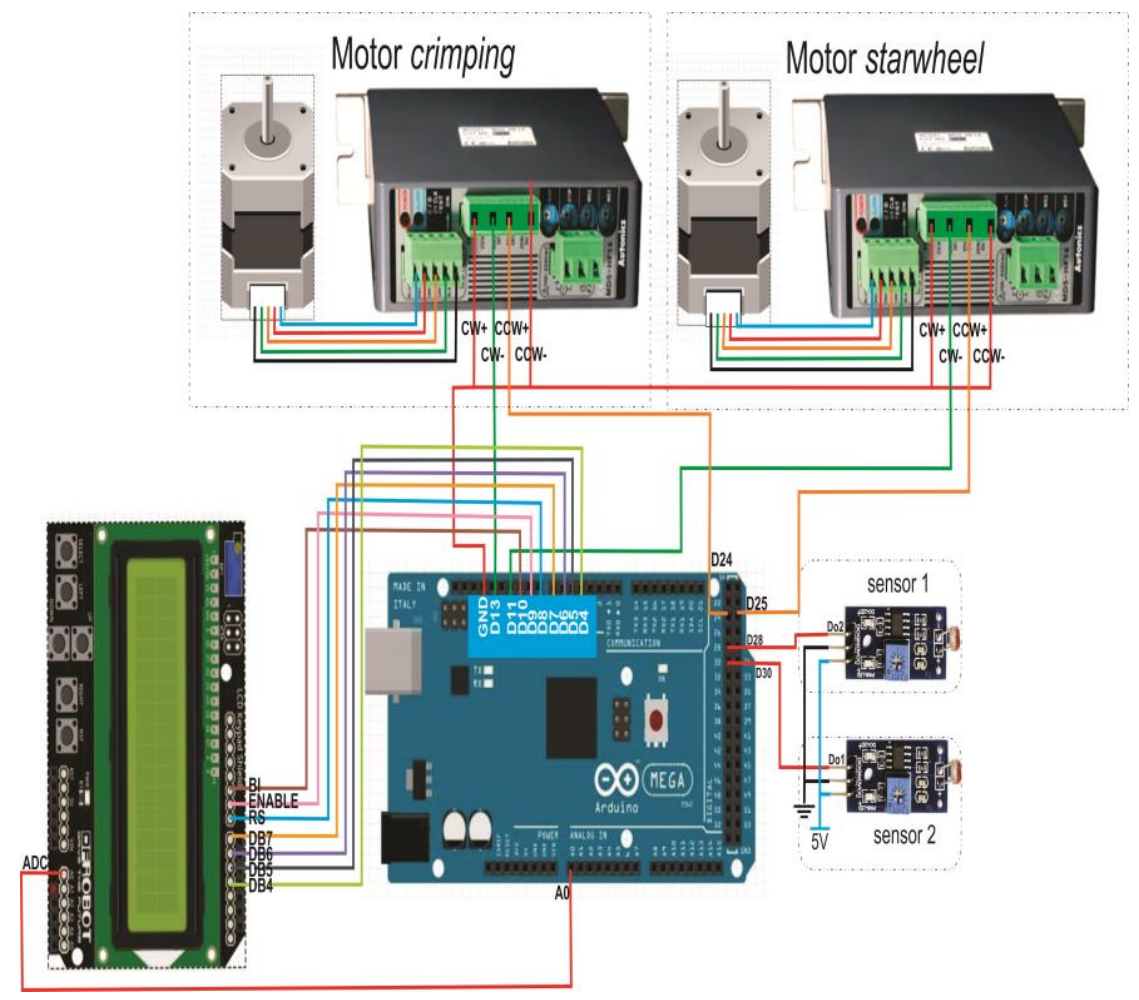

Gambar 10. Skema mesin capping

Tabel 1. Konfigurasi Pin Arduino

\begin{tabular}{||c||l||}
\hline Pin & \multicolumn{1}{|c||}{ Fungsi } \\
\hline \hline A0 & Keyboard (select, up, right, down, left) \\
\hline Pin 4 & DB4 \\
\hline Pin 5 & DB5 \\
\hline Pin 6 & DB6 \\
\hline Pin 7 & DB7 \\
\hline Pin 8 & RS (data atau sinyal display) \\
\hline Pin 9 & Enable \\
\hline Pin 10 & Kontrol intensitas background LCD \\
\hline Pin 11 & Mengatur pulsa sebanyak 5048x (starwheel 90 derajat) \\
\hline Pin 13 & Mengatur pulsa motor crimping \\
\hline Pin 24 & Pulsa ccw+ motor crimping \\
\hline Pin 25 & Pulsa ccw+ motor starwheel \\
\hline Pin 28 & Input sensor photosensitive 1 \\
\hline Pin 30 & Input sensor photosensitive 2 \\
\hline Pin 32 & Input limit switch \\
\hline
\end{tabular}




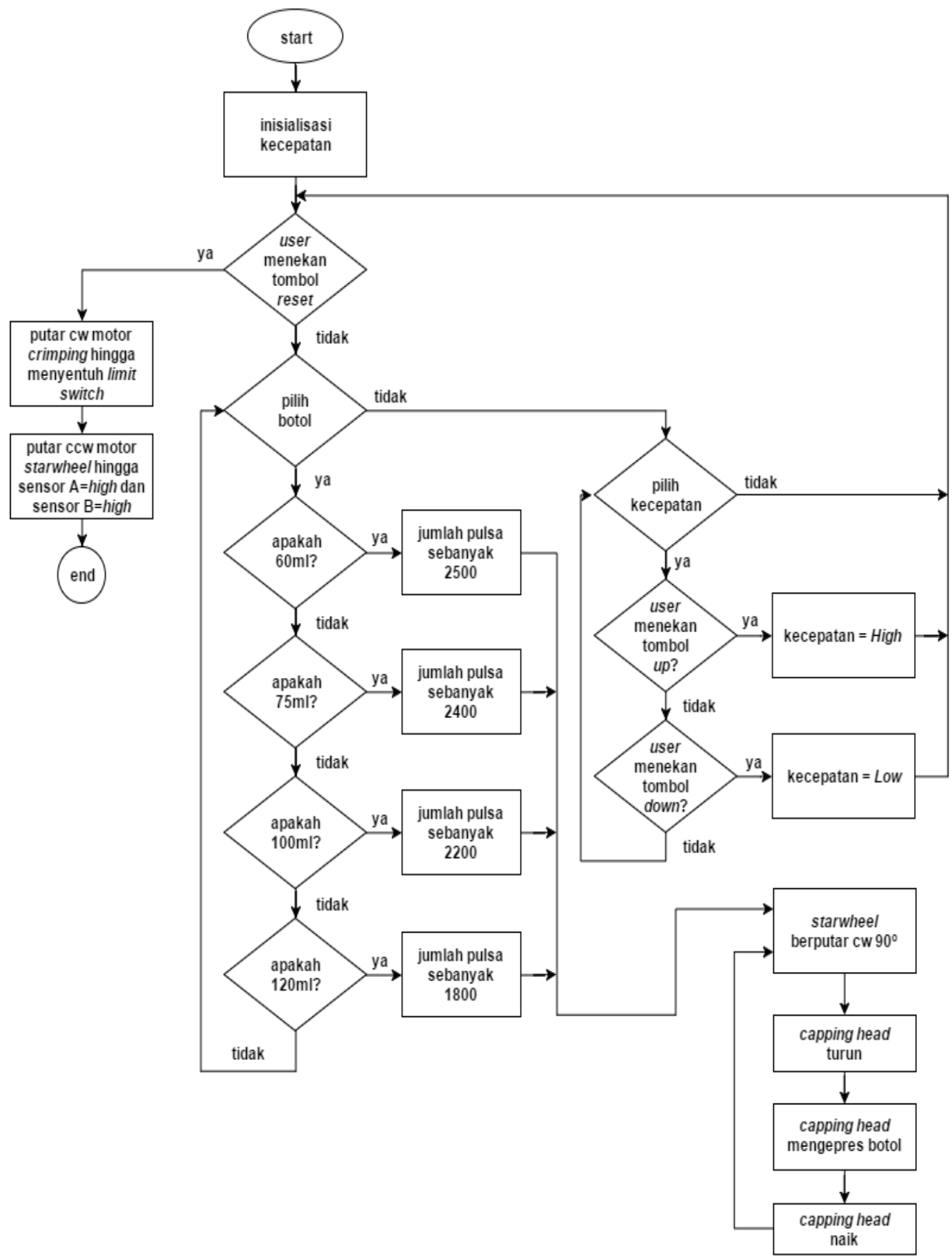

Gambar 11. Bagan alir perangkat lunak sistem mesin capping

\section{Hasil Pengujian}

Pengujian sistem dilakukan untuk mengetahui kapasitas produksi mesin capping per jam dan jumlah produk gagal untuk ukuran botol $60 \mathrm{ml}, 75 \mathrm{ml}, 100 \mathrm{ml}$, dan $120 \mathrm{ml}$. Pengujian ini juga digunakan untuk membandingkan sistem mesin capping otomatis dengan mesin capping manual. Tabel 2 sampai Tabel 6 memperlihatkan hasil pengujian yang dilakukan di PT. Mersifarma Tirmaku Mercusana, Sukabumi, Jawa Barat.

Dari hasil pengujian diperoleh hasil sebagai berikut. Untuk ukuran botol $60 \mathrm{ml}$ mengalami peningkatan kapasitas produksi sebesar 30\% dan produk gagal menurun $79 \%$. 
Untuk ukuran botol $75 \mathrm{ml}$ mengalami peningkatan kapasitas produksi sebesar $30 \%$ dan produk gagal menurun $79 \%$. Untuk ukuran botol $100 \mathrm{ml}$ mengalami peningkatan kapasitas produksi sebesar 33\% dan produk gagal menurun $75 \%$. Untuk ukuran botol $120 \mathrm{ml}$ mengalami peningkatan kapasitas produksi sebesar $36 \%$ dan produk gagal menurun $77 \%$.

Tabel 2. Pengujian jumlah produksi pada botol $60 \mathrm{ml}$ selama 1 jam

\begin{tabular}{|c||c|c|c|c|}
\hline \multirow{2}{*}{$\begin{array}{c}\text { Pengujian } \\
\text { ke- }\end{array}$} & \multicolumn{2}{|c|}{ Mesin capping manual } & \multicolumn{2}{c|}{ Mesin capping otomatis } \\
\cline { 2 - 5 } & Jumlah botol & Kerusakan tutup botol & Jumlah botol & Kerusakan tutup botol \\
\hline \hline 1 & 355 & 11 & 462 & 3 \\
\hline 2 & 357 & 15 & 462 & 3 \\
\hline 3 & 355 & 13 & 462 & 4 \\
\hline 4 & 351 & 16 & 462 & 3 \\
\hline 5 & 353 & 17 & 462 & 3 \\
\hline 6 & 354 & 19 & 462 & 4 \\
\hline 7 & 357 & 13 & 462 & 3 \\
\hline 8 & 357 & 15 & 462 & 3 \\
\hline 9 & 356 & 16 & 462 & 3 \\
\hline 10 & 353 & 12 & 462 & \\
\hline
\end{tabular}

Tabel 3. Pengujian jumlah produksi pada botol $75 \mathrm{ml}$ selama 1 jam

\begin{tabular}{|c||c|c|c|c||}
\hline \hline \multirow{2}{*}{$\begin{array}{c}\text { Pengujian } \\
\text { ke- }\end{array}$} & \multicolumn{2}{|c|}{ Mesin capping manual } & \multicolumn{2}{c|}{ Mesin capping otomatis } \\
\cline { 2 - 5 } & Jumlah botol & Kerusakan tutup botol & Jumlah botol & Kerusakan tutup botol \\
\hline \hline 1 & 357 & 19 & 462 & 4 \\
\hline 2 & 358 & 12 & 462 & 3 \\
\hline 3 & 350 & 10 & 462 & 4 \\
\hline 4 & 350 & 13 & 462 & 3 \\
\hline 5 & 352 & 17 & 462 & 3 \\
\hline 6 & 350 & 18 & 462 & 3 \\
\hline 7 & 354 & 17 & 462 & 3 \\
\hline 8 & 353 & 19 & 462 & 4 \\
\hline 9 & 356 & 20 & 462 & 3 \\
\hline 10 & 353 & 14 & 462 & \\
\hline
\end{tabular}

Tabel 4. Pengujian jumlah produksi pada botol $100 \mathrm{ml}$ selama 1 jam

\begin{tabular}{|c||c|c|c|c|}
\hline \multirow{2}{*}{$\begin{array}{c}\text { Pengujian } \\
\text { ke- }\end{array}$} & \multicolumn{2}{|c|}{ Mesin capping manual } & \multicolumn{2}{c|}{ Mesin capping otomatis } \\
\cline { 2 - 5 } & Jumlah botol & Kerusakan tutup botol & Jumlah botol & Kerusakan tutup botol \\
\hline \hline 1 & 358 & 14 & 480 & 3 \\
\hline 2 & 355 & 10 & 480 & 3 \\
\hline 3 & 358 & 12 & 480 & 3 \\
\hline 4 & 361 & 16 & 480 & 4 \\
\hline 5 & 358 & 10 & 480 & 4 \\
\hline 6 & 363 & 19 & 480 & 4 \\
\hline 7 & 359 & 11 & 480 & 3 \\
\hline 8 & 356 & 9 & 480 & 3 \\
\hline 9 & 358 & 14 & 480 & 3 \\
\hline 10 & 362 & 17 & 480 & \\
\hline
\end{tabular}


Tabel 5. Pengujian jumlah produksi pada botol $120 \mathrm{ml}$ selama 1 jam

\begin{tabular}{|c||c|c|c|c|}
\hline \hline \multirow{2}{*}{$\begin{array}{c}\text { Pengujian } \\
\text { ke- }\end{array}$} & \multicolumn{2}{c||}{ Mesin capping manual } & \multicolumn{2}{c|}{ Mesin capping otomatis } \\
\cline { 2 - 5 } & Jumlah botol & Kerusakan tutup botol & Jumlah botol & Kerusakan tutup botol \\
\hline \hline 1 & 357 & 15 & 491 & 4 \\
\hline 2 & 362 & 15 & 491 & 3 \\
\hline 3 & 362 & 14 & 491 & 4 \\
\hline 4 & 360 & 16 & 491 & 3 \\
\hline 5 & 358 & 18 & 491 & 4 \\
\hline 6 & 355 & 14 & 491 & 4 \\
\hline 7 & 359 & 11 & 491 & 3 \\
\hline 8 & 356 & 15 & 491 & 3 \\
\hline 9 & 359 & 14 & 491 & 3 \\
\hline 10 & 362 & 17 & 491 & \\
\hline
\end{tabular}

Tabel 6. Jumlah Produksi Rata-Rata per Jam

\begin{tabular}{|c|c|}
\hline Ukuran botol & Jumlah produksi rata-rata \\
\hline \hline $60 \mathrm{ml}$ & 462 botol \\
\hline $75 \mathrm{ml}$ & 462 botol \\
\hline $100 \mathrm{ml}$ & 480 botol \\
\hline $120 \mathrm{ml}$ & 491 botol \\
\hline
\end{tabular}

\section{Kesimpulan}

Mesin capping otomatis ini mampu menyegel botol dengan pilihan ukuran botol 60ml, $75 \mathrm{ml}, 100 \mathrm{ml}$, atau $120 \mathrm{ml}$ melalui keypad dan tampilan LCD. Mesin capping otomatis ini untuk ukuran botol $60 \mathrm{ml}$ mengalami peningkatan kapasitas produksi sebesar 30\% dan produk gagal menurun $79 \%$. Untuk ukuran botol $75 \mathrm{ml}$ mengalami peningkatan kapasitas produksi sebesar $30 \%$ dan produk gagal menurun $79 \%$. Untuk ukuran botol $100 \mathrm{ml}$ mengalami peningkatan kapasitas produksi sebesar 33\% dan produk gagal menurun $75 \%$. Untuk ukuran botol $120 \mathrm{ml}$ mengalami peningkatan kapasitas produksi sebesar $36 \%$ dan produk gagal menurun $77 \%$.

\section{Daftar Pustaka}

[1] A. Kadir, From Zero to a Pro, Andi Offset, 2014. 
